\title{
DORMIR, COMER E FALAR: ENLAÇAMENTO SIMBÓLICO
}

\section{ARTIGO ORIGINAL}

PALLADINO, Ruth Ramalho Ruivo1, SOUZA, Luiz Augusto de Paula², PALLOTTA, Mara Lucia ${ }^{3}$, COSTA, Rogério da ${ }^{4}$, CUNHA, Maria Claudia ${ }^{5}$

PALLADINO, Ruth Ramalho Ruivo. Et al. Dormir, comer e falar: enlaçamento simbólico. Revista Científica Multidisciplinar Núcleo do Conhecimento. Ano 06, Ed. 08, Vol. 06, pp. 153-170. Agosto de 2021. ISSN: 2448-0959, Link de acesso: https://www.nucleodoconhecimento.com.br/psicologia/enlacamento-simbolico, DOI: 10.32749/nucleodoconhecimento.com.br/psicologia/enlacamento-simbolico

\section{RESUMO}

O sono, a alimentação e a linguagem são pilares da vida saudável das crianças, estão entrelaçados desde o nascimento e compõem a estrutura dinâmica do desenvolvimento infantil. São efeitos de condições interdependentes: orgânicas, psíquicas e sociais, que envolvem a criança e resultam, simultaneamente, de heranças orgânica e simbólica. Essa última sobredetermina e modula a interação da criança com o ambiente, especialmente, com o outro humano que ali estiver. Essa herança desenhará padrões de conduta e comportamento que, muitas vezes, podem concorrer para alterações que comprometam, em alguma medida, o desenvolvimento geral da criança. Na clínica infantil, a descrição dos quadros de

\footnotetext{
${ }^{1}$ Doutora em Psicologia Clínica, professora doutora do Programa de Pós-Graduação em Comunicação Humana e Saúde da Faculdade de Ciências Humanas e da Saúde da PUC-SP (ORCID: https://orcid.org/0000-0001-8466838X).

${ }^{2}$ Doutor em Psicologia Clínica, professor titular do Programa de Pós-Graduação em Comunicação Humana e Saúde da Faculdade de Ciências Humanas e da Saúde da PUC-SP (ORCID: https://orcid.org/0000-0003-49689753).

${ }^{3}$ Doutoranda em Comunicação Humana e Saúde da PUC-SP (ORCID: https://orcid.org/0000-0001-5986-9657).

${ }^{4}$ Doutor em Filosofia, professor doutor do Programa de Pós-Graduação de Comunicação e Semiótica da PUC-SP (ORCID: https://orcid.org/0000-0002-6807-4263).

${ }^{5}$ Doutora em Psicologia Clínica, professora titular do Programa de Pós-Graduação em Comunicação Humana e Saúde da Faculdade de Ciências Humanas e da Saúde da PUC-SP (ORCID: https://orcid.org/0000-0003-31986995).
}

RC: 96051

Disponível em: https://www.nucleodoconhecimento.com.br/psicologia/enlacamentosimbolico 
transtornos do desenvolvimento, dos mais leves aos mais severos inclui, via de regra, aspectos alimentares, de sono e de linguagem, o que sugere, então, uma tríade de base, interrogando os clínicos quanto à possibilidade de aí haver, mais do que uma simples coincidência, uma correlação entre funções biológicas fundamentais. Se é assim, será importante o clínico se apropriar dessa perspectiva, uma vez que a implicação provavelmente determinará particularidades nas condutas de diagnóstico e de tratamento. Nessa direção, vale aprofundar e discutir o desenvolvimento dessas funções (sono, alimentação, linguagem), buscando esclarecer sua correlação constitutiva, o enlaçamento entre elas.

Palavras-chave: Linguagem, Alimentação, Sono.

\section{INTRODUÇÃO}

O sono, a alimentação e a linguagem são pilares da vida saudável das crianças, estão entrelaçados desde o nascimento e compõem a estrutura dinâmica do desenvolvimento infantil.

Tal entrelaçamento, contudo, não é um postulado unânime, nos projetos para a descrição e compreensão desta tríade ou cada parte é tomada separadamente ou, então, é apontado o privilégio de uma parte sobre as outras, quer dizer, seriam relações que não podem ser definidas como de implicação.

Para pensar a implicação é necessário supor que dormir, comer e falar envolvem o corpo, mas um corpo que demanda um nome, um corpo subjetivado e, portanto, um corpo enlaçado pelo simbólico: no enlaçamento do nome próprio e do corpo há, na leitura deste traço, algo que se articula pela via da apropriação, do próprio, que não é um elemento tão óbvio e simples na constituição humana (LEITE, 2008, p.16). Como se representa tal apropriação do corpo, que advém um corpo próprio ao ser nomeado? Nomear o corpo é reconhecê-lo no campo simbólico, efeito de infinitas articulações, ações e (en)laços. 
Padrões de sono, de alimentação e de fala são efeitos de condições interdependentes: orgânicas, psíquicas e sociais, que envolvem a criança e resultam, simultaneamente, de heranças orgânica e simbólica. Essa última sobredetermina e modula a interação da criança com o ambiente, especialmente com o outro humano que ali estiver.

Para os bebês, esse ambiente pode ser representado, privilegiadamente, pela figura materna, a mãe e, vale notar, não se trata nem, necessariamente, da mãe biológica nem de entes cuidadores, mas de uma instância maternante asseguradora, de um outro humano que inscreve o "próximo-que-socorre", o nebensmench freudiano, como esclarece Cabassu (2003). Aquele que, mais do que garantir a sobrevivência do organismo da criança, a reconhece como sujeito, constitui o laço entre desejo (maternante) e palavra, a partir do qual a subjetividade e as relações sociais tornamse possíveis e iniciam-se para o bebê, pela nomeação de seu corpo e sua inscrição em um texto de filiação e sociabilidade.

Se, como dissemos, sono, alimentação e linguagem são pilares da vida da criança, sua implicação depende, portanto, dos enunciados maternos dirigidos a ela, mas apenas se eles - para saciar a fome, aquecer do frio, embalar para dormir... - forem acompanhados de um desejo não anônimo (STORK, LY, MOTA,1997, p. 34): eis a presença do outro, a instituição da relação maternante.

Mais ainda, importa saber que é preciso reconhecer nas atitudes maternas um sentido cultural, igualmente determinante, porque as mães interpretam e respondem às manifestações [...] do bebê em função das normas da sociedade a que pertencem, mesmo se suas respostas são também moduladas pela dinâmica psíquica pessoal (CISMARESCO, 1997, p. 267).

Essa condição supõe, mais amplamente, a centralidade da função de uma família continente, para a qual o conceito "eu-pele" de Anzieu (1989) pode ser esclarecedor, uma vez que se refere aos limites entre o biológico e o simbólico e, para o bebê, sua instauração responde à necessidade de um envelope narcísico e assegura ao 
aparelho psíquico a certeza e a constância de um bem-estar de base (op. cit., p. 44). Esse sentimento de segurança será fundamental ao sentimento de pertencimento, básico à construção da identidade da criança.

Essa herança, a um só tempo orgânica e simbólica, transmitida nas relações da criança com o outro, aliada - é claro - à herança orgânica, desenhará padrões de conduta e comportamento que, muitas vezes, podem concorrer para alterações que comprometam, em alguma medida, o desenvolvimento geral da criança.

$\mathrm{Na}$ clínica infantil, a descrição dos quadros de transtornos do desenvolvimento, dos mais leves aos mais severos inclui, via de regra, aspectos alimentares e de sono (WINNICOTT, 1975; MADEIRA, AQUINO, 2003 ; SANTOS, 2004; JERUSALINSKY, 2004).

O fato desses sintomas apresentarem-se, quase sempre, alinhados entre si interroga os clínicos quanto à possibilidade de aí haver, mais do que uma simples coincidência, uma correlação entre funções biológicas fundamentais.

Além disso, nas descrições clínicas dos transtornos do desenvolvimento da linguagem, relatos de problemas de alimentação (PALLADINO, CUNHA, SOUZA, 2007) e de sono são frequentes, o que sugere, então, uma tríade de correlações.

Todavia, e com frequência, os diferentes campos de estudo do desenvolvimento não compartilham a ideia de haver correlação significativa entre tais funções, sendo comum que as questões de sono, de alimentação e de linguagem sejam pensadas separadamente. Quando é assim, na presença de alterações de desenvolvimento, o fenômeno é assumido como comorbidade.

Há exceções e tal predominância, é fato, com relevância à psicanálise e a certas abordagens da psicologia (GROMANN,2002), bem como à pequena parcela de estudos de disciplinas que dialogam com ambas, como a fonoaudiologia, a medicina psiquiátrica, a neurologia e a endocrinologia. Essas exceções inspiraram uma nova reflexão.

RC: 96051

Disponível em: https://www.nucleodoconhecimento.com.br/psicologia/enlacamento$\underline{\text { simbolico }}$ 
Assumir as correlações entre as funções torna possível esclarecer o alinhamento sintomatológico observado entre os sintomas alimentares, de sono e de linguagem na primeira infância. Se é assim, será importante o clínico se apropriar dessa perspectiva, uma vez que a implicação provavelmente determinará particularidades nas condutas de diagnóstico e de tratamento.

Nessa direção, vale aprofundar e discutir o desenvolvimento dessas funções (sono, alimentação, linguagem), buscando esclarecer sua correlação constitutiva, o enlaçamento entre elas.

\section{ALIMENTAÇÃO E LINGUAGEM: A SURPRESA NA OBSERVAÇÃO}

Há algum tempo, no cotidiano da clínica infantil, uma observação, de poder indiciário, começou a nos interrogar.

Isto se deu em face de repetidas narrativas parentais sobre questões alimentares nas anamneses incluídas em procedimentos avaliativos ou mesmo no acompanhamento dos planos terapêuticos no caso de crianças com diversos problemas de desenvolvimento de linguagem. Na lida com essas crianças, cedo ou tarde, queixas sobre a alimentação surgiam, indo de idiossincrasias a distúrbios de deglutição, e sua insistente repetição foi o que ganhou lugar em nossa escuta clínica e, com isso, o valor indiciário da observação ganhou relevância.

A partir dessas observações, estruturamos pesquisa com casuística de 35 pacientes, e as evidências obtidas esclareceram concomitância importante entre problemas de linguagem e alimentares, sugerindo correlação significativa entre eles (PALLADINO, CUNHA, SOUZA, 2004 e 2007).

Uma leitura psicanalítica da questão, oferecida pela Revista Francesa de Ortofonia (2004), permitiu revestir teoricamente os resultados da referida pesquisa, levandonos a pensar a correlação entre problemas de linguagem e alimentação sob a noção de oralidade, como proposta por Thibaut (2006, p. 115): a zona oral é uma das zonas erógenas corporais, isto é, um espaço sustentado pulsionalmente, no qual

RC: 96051

Disponível em: https://www.nucleodoconhecimento.com.br/psicologia/enlacamentosimbolico 
muitas funções se embaralham no plano comum do funcionamento simbólico. $A$ boca (órgão) é, neste sentido, território da alimentação, da linguagem e dos afetos.

Em outras palavras, a zona oral é o campo somático no qual a oralidade, como plano psíquico, entrelaça simbolicamente a alimentação e a linguagem.

\section{ALIMENTAÇÃO, LINGUAGEM E SONO: UMA NOVA ARTICULAÇÃO}

Aquele reposicionamento conceitual encaminhou e desdobrou nossa escuta clínica para outros espaços, levando-nos, mais recentemente, a retrabalhar a relação alimentação e linguagem a partir da inclusão do sono, conformando uma tríade constitutiva da criança. O sono foi incluído pois é, também, protagonista na cena fundamental da constituição da criança (PALLADINO, 2016, 2018). O sono está vinculado à cena de alimentação do bebê e faz parte das narrativas parentais em caso de crianças com problemas no desenvolvimento de linguagem, embora ainda opacizado, isto é, considerado sem valor ou com pequeno valor indiciário em termos de risco ao desenvolvimento infantil.

Assumindo a correlação constitutiva entre as referidas funções, será necessário esclarecer o alinhamento sintomatológico observado entre os sintomas alimentares, de sono e de linguagem, bem como analisar possíveis implicações nas condutas de diagnóstico e de tratamento nesses casos.

O sono, uma função biológica fundamental, importante para o restauro do metabolismo energético cerebral e para a consolidação da memória (CABALLO, NAVARRO, SIERRA, 2002), bem como para o próprio equilíbrio psicológico, resulta de uma gradativa organização temporal, estrutural e fisiológica do ritmo sono-vigília (GEIB, 2007; PIAULINO DE ARAÚJO, 2012.) É um estado de funcionamento cerebral com duas fases diferentes e mensuráveis: sono REM (Rapid Eye Movement) e sono NREM (No Rapid Eye Movement). As diferenças se dão, sobretudo, em termos de mecanismos metabólicos com consequentes modificações

RC: 96051

Disponível em: https://www.nucleodoconhecimento.com.br/psicologia/enlacamento$\underline{\text { simbolico }}$ 
dos processos fisiológicos e das condições posturais. No sono REM há um aumento nos níveis metabólicos, certa atonia muscular, redução da temperatura corporal, ritmo respiratório equilibrado (com poucas e breves apneias), movimentos oculares rápidos, podendo haver, no caso das crianças, choro/sorrisos/gemidos. No sono NREM há diminuição nos níveis metabólicos, diminuição da frequência respiratória e da mobilidade corporal (JOHN, 2000). Nessa fase há um extenso trabalho de regeneração celular e na outra, a fase REM, regeneração principalmente psicológica, pois aí se dá a maior parte dos sonhos.

O sono REM e NREM alternam-se, bem como alternam-se os estados de sono e vigília. O ciclo entre estados de sono e de vigília, no início apenas biologicamente determinado, começa a organizar-se ainda em fase fetal e sua constituição tem estreita relação com o desenvolvimento do Sistema Nervoso Central (GEIB, 2007). Aos poucos, tal organização sofre o impacto de estímulos exógenos, como luminosidade intensa, sons variados e, sobretudo, a presença humana, fazendo com que o ciclo sono-vigília passe a ter um ritmo marcado por essa dupla interferência endógena e exógena.

Ao nascimento, o padrão do sono do bebê - essencialmente fisiológico - é mais simples, com dois estados, ativo (sono REM) e tranquilo (sono NREM), num ritmo sono-vigília denominado ultradiano, ainda não dominado pela alternância dia-noite. Os ciclos alternam-se em tempo mais curto, sendo que, nos primeiros meses, o estado ativo é predominante: o bebê dorme a qualquer hora e acorda muito facilmente, sendo a vigília anunciada pelo choro e só mais tarde se observa a vigília quieta. Ao longo do tempo, esse ritmo é modificado pelo ambiente, provocando algumas atipias anárquicas, isto é, mudanças no começo completamente desorganizadas e desorganizadoras do ciclo do sono, não só pelos estímulos luminosos e sonoros mas, principalmente, pela ação humana, que acaba modulando o ritmo que, enfim, torna-se cicardiano, com longos períodos noturnos de sono tranquilo ou mesmo de vigília mais quieta. (PIAULINO DE ARAÚJO 2012; JOHN, 2000)

RC: 96051

Disponível em: https://www.nucleodoconhecimento.com.br/psicologia/enlacamento$\underline{\text { simbolico }}$ 
Uma ação humana prevalente na questão do sono dos bebês é a alimentação, por dois motivos principais: frequentemente antecede o momento do bebê dormir, além do fato de depender de outro ser humano para sua efetivação. Assim, o que no início tem uma determinação apenas endógena, passa a sofrer influência do meio externo. Aí é que os ritmos ultradiano e cicardiano consolidam-se e começam a alternar-se, passando o primeiro a reger a distribuição das fases do sono e o segundo os estados de sono e vigília, ganhando o sono a noite e a vigília o dia (PIAULINO DE ARAÚJO, 2012; JOHN, 2000).

Ao tomar em seu colo o bebê para amamentá-lo, a mãe the oferece um campo afetivo inigualável: o prazer em sorver o leite, em sentir o cheiro, em ouvir as palavras, em experimentar o roçar do corpo do outro, esse deleite o faz adormecer, entregar-se.

Sono e alimentação estão, assim, para além do registro da necessidade e, mais do que isso, constituem-se em um entrelaçamento definitivo (PENHA, 2002; FÉDIDA,1977). Como mencionado, essas funções do bebê dependem de outro ser humano para sua devida realização e, por esse motivo, ganham caráter simbólico, conformando-se como experiências psíquicas. Tais experiências, em geral de prazer, deixam marcas psíquicas e trilhamentos cerebrais, criando memórias potentes, que convocam os sujeitos ao convívio com o outro.

A mãe vai amamentar seu bebê, falando e/ou cantando para ele, acariciando-o, o que, junto com a saciedade, aquieta a criança e fomenta o sono. No entanto, a fome vai, tempos depois, despertar o bebê, repetindo-se o ciclo vigília-sono.

Significa dizer que esse ciclo contínuo não será efeito apenas do ritmo orgânico mas, também, de um ritmo psíquico, impresso pela mãe (FARIAS, 2004), por meio de seus cuidados.

Em outras palavras, o seio (ou a mamadeira) torna-se um campo de trocas e lugar de inserção do sono (FOLINO, LOPES DE SOUZA, 2013), o falar/ cantarolar e o embalar constituem o ethos dessas práticas de adormecimento. Laznik-Penot (1997, 
p. 37) mostrou a importância crucial da melopéia materna - a música da voz da mãe que conversa com o bebê. Essa cena de acalento, em sua vez, implica a alimentação, dá a ela existência também simbólica.

Em última instância, esse ritual íntimo e repetido, que envolve corpo e palavras, dormir e comer, vai constituir a cena fundamental da humanização, compondo o plano relacional no qual inaugura-se o laço entre o bebê e sua mãe. Aliás, essa perspectiva corrobora ideias de Spinoza (2007) sobre os afetos e suas consequências em termos de alegria ou tristeza: mãe e bebê afetam e são afetados um pelo outro, o que perfaz uma rede de conexões afetivas que os constitui enquanto tais, frequentemente ampliando a potência para agirem naquela relação singular e em todas as outras. O aumento da potência de agir no mundo é o que Spinoza denomina alegria.

Entretanto, nem sempre os afetos entre mãe e bebê são aumentativos da potência, às vezes pode acontecer o contrário. Vejamos um exemplo relativamente comum: mães que passam pelo baby blues (depressão benigna, transitória, potencialmente produtiva, pois faz parte das modificações geradas pela vinda de um bebê) e não encontram possibilidade de elaboração e acolhimento pelo contexto social que, muitas vezes, só reconhece o nascimento de um filho pelos sentimentos de felicidade e plenitude que, culturalmente, ele deveria produzir (FOLINO, LOPES DE SOUZA, 2013).

Essas mães deprimidas passam menos tempo olhando, tocando, falando com seus bebês, mostram menos responsividade, espontaneidade e menores índices de atividade com seus bebês. A depressão pós-parto contribui para que os afetos na díade tornem-se assincrônicos, na medida mesma em que a mãe encontra-se pouco ou não-responsiva (SERVILHA, RAAD BUSSAB, 2015). Durante esse período, o processo afetivo entre mãe e bebê não aumenta a potência de ambos, ao contrário, a reduz, podendo até desdobrar, em alguns casos, questões ou transtornos psíquicos para as mães e para o desenvolvimento do bebê. A diminuição da potência de agir é, por sua vez, o que Spinoza chama de tristeza. 
É fundamental o fato de que o ciclo alimentação-acalento-sono representa variadas experiências psíquica para o bebê, que implicam sentidos ambíguos para o bebê: alimentação e acalento tornam-se espaço e tempo da interação mãe-bebê, e o sono da separação entre eles - ao adormecer, o bebê é colocado no berço. O dormir vai representar um corte, intervalo ou descontinuidade no enlaçamento original entre a criança e sua mãe. O ritual contém, em si mesmo, a ambiguidade entre acolhimento e separação. Essa posição da mãe, dupla, ambígua, delicada, é encenada quando ela canta e a criança adormece para ser colocado no berço: aproximação amorosa e separação.

Aos poucos, a mãe espaça as mamadas - oportunidade de consolidação do estado de vigília -, bem como introduz sucedâneos, que se interpõem entre seu próprio corpo e o do bebê como substitutos de sua presença: chupetas, paninhos e brinquedos, até a palavra metafórica, aquela que traz a mãe, a representa para o bebê. Esses sucedâneos são inseridos para operar deslocamentos na relação fusional que perfaz os primeiros tempos do laço mãe-bebê, são suportes para o bebê enfrentar a angústia da separação que o dormir anuncia, da sensação de que o sono determina a ausência da mãe, privação do meio que lhe assegura a vida e o prazer.

Note-se que a necessidade de se operar deslocamentos para o adormecimento é mantida e atualizada na idade adulta, nos rituais que antecedem o deitar: banhos, chás, leituras... . É como se estes rituais afastassem o "perigo" que a solidão do dormir impõe, e garantissem uma espécie de proteção asseguradora para o adormecimento. Vários idosos manifestam dificuldade de adormecimento pelo medo da morte (GEIB, et all, 2003): angústia da perda de si e do mundo. O adulto conta com o funcionamento internalizado da instância maternante asseguradora, operando os deslocamentos, criando os sucedâneos daquela que foi a primeira guardiã do sono, agora inconscientemente revivida, por exemplo, com massagens, práticas sensuais, ingestão de alimentos, bebidas ou fármacos. 
Durante a infância, em cada cultura e variando em razão de condições sociais e econômicas, são diversas as formas de contornar essa angústia do dormir (por ambos, mãe e bebê): co-leito (pleno ou parcial), quarto compartilhado e a presença do (necessário) aleitamento noturno (BLAIR, 2008).

Mas, é importante observar, os clínicos e pesquisadores tendem a se referenciar no chamado "padrão ouro" do sono infantil das sociedades ocidentais ditas desenvolvidas, um padrão buscado precocemente: leito individual, quarto separado dos pais, ausência de alimentação noturna.

Contudo, há alertas diferentes em relação à questão do sono, pois importa também os participantes da cena e os hábitos do sono, constitutivos externos dos ciclos de sono (GEIB, 2007). Minimamente, há de se supor que para uma criança que não adormece ou tem sucessivos despertares, pode haver uma mãe que não cogita separar seu corpo do corpo de seu bebê, em parar de falar com ele, cantarolar para ele, acarinhá-lo...

Uma possibilidade de contornar essa angústia é o desejo do sonho, instância em que aquilo que se perdeu ou se ausentou pode ressurgir oniricamente.

Inicialmente, os estudos postulavam que os sonhos constituíam uma atividade exclusiva da fase REM do sono. Porém, pesquisas mais recentes mostram que não há exclusividade, embora exista predomínio dessa atividade na fase REM, com reconhecimento pelos estudiosos de que ela se destina a garantir que o sono realize sua função regeneradora (GROMANN, 2002).

Os sonhos são um efeito do adormecimento das censuras, que impedem sensações, sentimentos e ações; censuras que habitam a mente de todos, perturbando tanto a vigília quanto o próprio sono. $\mathrm{O}$ adormecimento abre espaço para o que se denomina elaboração onírica, quer dizer, construção de pensamentos livres de interdição. Por essa razão, tem-se que os sonhos realizam o restauro psíquico, tão importante quanto o restauro físico, operado sobretudo na fase NREM. 
No desenvolvimento da criança, as fases do sono sucedem-se gradativamente para organizar adequadamente o sono, fazendo com que ele sirva de tela para os sonhos: do sono fisiológico ao simbólico. O bebê precisa construir o caminho entre comer, fechar os olhos, perder sua mãe (de vista!) e reencontrá-la nos sonhos (PENHA, 2002).

Assim como para o sono, há um padrão-ouro para a alimentação, produzido, sobretudo, culturalmente (ainda que aspectos orgânicos sejam aí considerados). No ocidente: amamentação até pelo menos seis meses, desmame natural, introdução de pastosos e sólidos, um caminho que, rapidamente, deve ir do líquido morno, de gosto indefinido, à comida sólida, quente, salgada, em cenas familiares que envolvem o desempenho individual.

Porém aqui, tal como na questão do sono, há vários conteúdos em jogo, que particularizam a cena e merecem atenção (JERUSALINSKY, 2004; MADEIRA, AQUINO, 2003).

É possível fazer um paralelo e dizer que para uma criança que chora, engasga, rumina, vomita e/ou recusa alimentação, além de eventuais problemas anatomofisiológicas, pode haver uma mãe que tem dificuldade em se posicionar como o outro assegurador do sujeito em constituição, desempenhando inadequadamente a cena alimentar, sem alegria ou até com tristeza.

Uma cena metafórica dessa dificuldade representa-se no desmame, um processo gradual, que merece delicadeza, uma vez que é sustentado por operações simbólicas de separação e, portanto, não é um acontecimento "natural", óbvio, cuja oferta de alimentos e a passagem de certos tipos a outros sejam sempre tranquilas.

\section{O ALINHAVO DA LINGUAGEM}

A linguagem é a ação humana prevalente nas questões do sono e da alimentação. Ambas as funções constituem vivências simbólicas nas palavras maternas e nas palavras infantis imaginadas pela mãe. Na cantiga, na história, nas interjeições da

RC: 96051

Disponível em: https://www.nucleodoconhecimento.com.br/psicologia/enlacamentosimbolico 
mãe e no sugar, no olhar, no fechar de olhos, nos sons inarticulados que são os "enunciados" do bebê. Faz-se a cena dialógica como um "jogo de palavras", na interpretação baktiniana. Um diálogo fundante que perdura e marca a entrada do sujeito na língua, um território de encontros e confrontos entre subjetividades: embate polifônico de diferentes instâncias sociais, coexistência conflituosa de vozes e efeitos de sentido. Isso se dá desde o início, a começar da própria polifonia da fala materna, calcada numa posição ambivalente diante de seu bebê recém chegado.

A fala da mãe não provoca um efeito direto em seu bebê, mas o alcança por meio do efeito que provocou nela mesma (CORIAT, 2000), o que faz da relação com o bebê um campo revelador, que pode lançá-la numa vivência de puro prazer, ou não. O que incide imediatamente sobre o bebê é a voz da mãe, essa melodia maternante, dimensão musical e poética portadora de valores afetivos (LAZNIK-PENOT, 2013), que envolve e sustenta o bebê, completamente dependente. Melodia que cria a cena de alimentação e de adormecimento. O bebê guarda especial atenção à voz da mãe e, na sua ausência, à qualquer voz melódica que porte afetos. Assim é que ele vai compondo a interação com os outros de seu entorno.

Essa voz-afeto, por meio de sutilezas, dinâmica e rugosidade (variação de sentidos e sensações), é espaço de expressão espontânea do inconsciente materno (FÓNAGY apud LAZNIK-PENOT, 2013). Por essa razão, importa notar se, nessa fala melódica, palavras doces são produzidas, ou se, a partir da ambivalência materna, essa voz pode também produzir, nos seus ruídos, outras (palavras) bem estranhas (LAZNIK-PENOT, 2013, p. 130). Esse parece ser um caminho para entender quando a interação não é exitosa.

O berço melódico da fala da mãe acolhe o bebê e o joga na dimensão simbólica da existência humana, como alerta Melgaço (2013, p.10) quando diz que o processo civilizatório coloca o poder das palavras em destaque. 
À voz da mãe o bebê apresenta-se com seu olhar, seus movimentos, seus sons, e no vai-e-vem entre os dois os jogos de interação são montados, banhando com palavras a relação em que mãe e bebê se ajeitam.

São tempos constitutivos primordiais, no quais é possível haver impasses e, quando eclodem, deflagram sintomas, expressões que encontram vazão na alimentação, no sono e na linguagem, na medida em que essas funções concernem, centralmente, a relação entre o bebê e sua mãe.

Nessa medida e por fim, o cerne da questão não está nem na mãe nem em seu bebê, mas na relação entre eles, num processo não de similitude, mas de identificação, marcado inicialmente pelo fato de que quando os bebês ainda não falam, este âmbito relacional é tracejado, sobretudo, pelos processos mentais da mãe, o que seria o primeiro tempo da constituição da lógica psíquica e, como pontua Vorcaro (2005, p. 24), do enxame significante produzido no campo do Outro, em que o ser vivo está imerso, surge o "lugar prévio" do sujeito como efeito da linguagem. Dessa forma, o que resta inconsciente na mãe encontra-se mais suscetível a inscrições e revelações pelo bebê (CHAVES, 2013, p. 228).

O dormir, o comer e, porque não apontar, o olhar/ser olhado - primeiras "palavras" do bebê - são o palco das revelações para a mãe e seu bebê. Nessa singular relação, o desabrochar de funções pilares da vida da criança dependerá do longo caminho entre a posição de objeto (da e para a mãe) e a de sujeito.

\section{CONSIDERAÇÕES FINAIS}

Como foi dito, este estudo emerge da clínica e, sugerimos, que a ela deva retornar. Ou seja, diante de queixas relacionadas a transtornos no sono, na alimentação e na linguagem é relevante que o profissional da saúde atente às possíveis demandas resultantes da articulação simbólica entre essas três dimensões; articulação inerente ao funcionamento humano quando se supõe a indissociabilidade entre linguagem, corpo e psiquismo.

RC: 96051

Disponível em: https://www.nucleodoconhecimento.com.br/psicologia/enlacamento$\underline{\text { simbolico }}$ 
Se é assim, talvez o sonho possa também ser incluído em futuros estudos sobre a intrincada implicação simbólica aqui trabalhada.

\section{REFERÊNCIAS}

ANZIEU, D. O Eu-pele. São Paulo: Casa do Psicólogo, 1989.

BLAIR, O. S. O co-leito em perspectiva. Jornal de pediatria, 84(2), 99-101, 2008.

CABALLO, V. E., NAVARRO, J. F. e SIERRA, J. C. Tratamento comportamental dos transtornos do sono In: CARLSON, N. R. Fisiologia do Comportamento. 7ed, SP: Manole, 2002.

Cabassu G. Palavras em torno do berço. In: Wanderley D. B. (org) Palavras em torno do berço. Salvador, Ágalma, 2003.

CHAVES, M. P. C. T. O lugar do analista na clínica com bebês. In: BUSNEL M. C. e MELGAÇO R. G. (orgs) $O$ bebê e as palavras: uma visão transdisciplinar sobre o bebê. Instituto Langage, 2013.

CISMARESCO, A. S. O grito neonatal e suas funções. (seção: o grito e as reações fisiológicas e emocionais das mães). In: BUSNEL, M. C. A linguagem dos bebês. São Paulo, Escuta ed., 1997.

CORIAT, E. Os flamantes bebês e a velha psicanálise. Estilos da Clínica. V.5, n.8, 2000.

FARIAS, C. N. F. e GOMES DE LIMA, G. Relação mãe-criança: esboço de um percurso na teoria psicanalítica. Revista Estilos da Clínica, ano IX, n. 16, 2004.

FÉDIDA, P. Le conte et la zone de l'endormissement. In: Corps de vide et espace de séance. Paris, Jean Pierre Delaye, 1977. 
FOLINO, C. S. G. e LOPES DE SOUZA, AS. As Reverberações do encontro mãebebê: sobre a depressão e a depressividade pós-parto. In: BUSNEL, M. C. E MELGAÇO, R. G. (orgs) $O$ bebê e as palavras: uma visão transdisciplinar sobre o bebê. Instituto Langage, 2013.

GEIB, L. T. C., CATALdO NETO,A, WAINBERG R, NUNES ML. Sono e envelhecimento. Rev. Psiquiatria. Rio Gd. Sul, 25(3):453-465, 2003.

GEIB, L. T. C. Desenvolvimento dos estados do sono na infância. Revista Brasileira de Enfermagem, 60(3):323-26, 2007.

GROMANN, R. M. G. Sonho e psiquismo: o labirinto entre o corpo e a subjetividade. Pulsional Revista de psicanálise, 164: 27-34, 2002

JERUSALINSKY, A. Psicanálise e desenvolvimento infantil. Porto alegre, Artes e Ofícios, 2004.

JOHN, M. W. Sensitivity and specificity of the multiple sleep latency test (MSLT), the maintenance of wakefulness test and the Epworth sleepiness scale: failure of the MSLT as a gold standard. J. Sleep Res, 9: 5-11, 2000.

LAZNIK-PENOT, M. C. Rumo à palavra. São Paulo, Escuta ed., 1997.

LAZNIK-PENOT, M. C. Linguagem e comunicação do bebê de zero a três meses. In: LAZNIK-PENOT, M. C. A hora e a vez do bebê. Instituto Langage, 2013.

LEITE, C. A. O. Quando o corpo pede um nome. Tese de doutorado, Instituto de Estudos da Linguagem, UNICAMP, 2008.

MADEIRA, I. R. e AQUINO, L. A. Problemas de abordagem difícil: "não come" e "não dorme". J Pediatr, 79 (Supl 1): 43-54, 2003.

MELGAÇO, R. G. Prefácio. In: BUSNEL, M. C. e MELGAÇO, R. G. (orgs) O bebê e as palavras. São Paulo, Instituto Langage, 2013.

RC: 96051

Disponível em: https://www.nucleodoconhecimento.com.br/psicologia/enlacamentosimbolico 
PALLADINO, R. R. R.; CUNHA, M.C. e SOUZA, L. A. P. Transtornos de linguagem e transtornos de alimentação em crianças. Revista Psicanálise e Universidade, 21: 95-108, 2004.

PALLADINO, R. R. R.; CUNHA, M.C. e SOUZA, L. A. P. Transtornos de linguagem e de alimentação: coincidências ou co-ocorrências? Pró-fono Revista de Atualização Científica, 19, 205-214, 2007.

PALLADINO RRR. Linguagem e sono. Anais do XXIV Congresso Brasileiro de Fonoaudiologia, Sociedade Brasileira de Fonoaudiologia, São Paulo, 2016

PALLADINO RRR. Sono e alimentação: funções psíquicas associadas. Anais do III Congresso Iberoamericano de Fonoaudiologia e XXVI Congresso Brasileiro de Fonoaudiologia. Sociedade Brasileira de Fonoaudiologia, Curitiba, 2018.

PENHA, N. C. G. Dormir nos braços da mãe: a primeira guardiã do sono. $\quad$ Rev Psichê, 6(10):65-84, 2002.

PIAULINO DE ARAÚJO, P. D. Validação do questionário do sono infantil de Reimão e Lefèvre (QRL). Tese de doutorado, Departamento de Neurologia, USP, 2012.

RÉÉDUCATION ORTHOPHONIQUE, 44 année, juin/2006, trimestriel n. 226 - La deglutition Dysfunctionnelle, 2006.

SANTOS, M. C. Problemas alimentares da infância sem diagnóstico clínico: quando vigiar, quando atuar? Rev. Hospital de Crianças Maria Pia, vol. XIII, n.4: 342-7, 2004.

SERVILHA, B. e RAAD BUSSAB, V.S. Interação Mãe-Criança e Desenvolvimento da Linguagem: a Influência da Depressão Pós-Parto. Psico, Porto Alegre, v. 46, n. 1, pp. 101-109, jan.-mar. 2015. 
SPINOZA, B. Ética. Trad. e notas de Thomaz Tadeu. Belo Horizonte, Autêntica Ed. 2007.

STORK, H.; LY, O. e MOTA. G. Os bebês falam: como você os compreende? Uma comparação intercultural. In: BUSNEL, M. C. (org) A linguagem dos bebês. Sabemos escutá-los? São Paulo: Escuta Ed., 1997.

THIBAULT, C. A língua, órgão chave das oralidades. Rééducation Orthophonique, 44 année, juin/2006, trimestriel, n.226 - La deglutition Dysfunctionnelle, p.115, 2006.

VORCARO, A. Crianças em Psicanálise, Rio de Janeiro, Companhia de Freud, 2005.

WINNICOTT, D. W. Pensando sobre crianças. Porto Alegre, Artmed, 1975.

Enviado: Setembro, 2021.

Aprovado: Setembro, 2021. 